Book Review

ISSN: 2162-3104 Print/ ISSN: 2166-3750 Online

Volume 8, Issue 2 (2018), pp. 1264-1266

(C) Journal of International Students

http://jistudents.org/

doi: $10.5281 /$ zenodo. 1250427

\title{
American Community Colleges: The International Student's Guide
}

Shane, C. J. (2017). American community colleges: The international student's guide. Tucson, AZ: Rope's End Publishing.

Reviewed by: Nara M. Martirosyan, Sam Houston State University (USA)

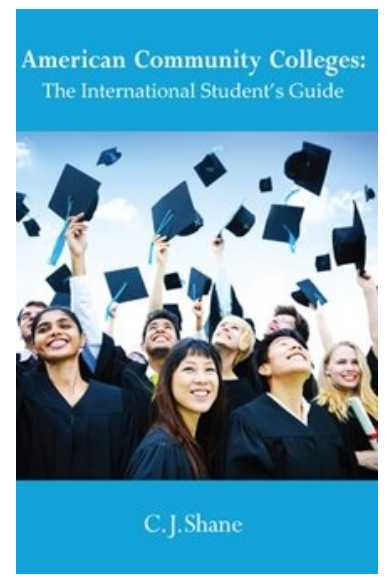

institutions.

The American Community Colleges: The International Student's Guide, a recently published book by Shane (2017), offers comprehensive information about the educational opportunities provided by the community colleges, and helps readers to understand the benefits of starting their undergraduate education from a community college. This book consists of 11 chapters. Chapter 1 is a description of how community colleges fit into the U.S. higher education system, benefits of starting higher education at community colleges, and steps of studying at an American community 
college. Two notable benefits cited by the author are lower tuition costs and expanded academic options and support (e.g., small class sizes, wide choice of programs and courses, English language support, etc.).

Chapter 2 offers tips on how to choose a community college. Some factors to consider are academic and career goals, accreditation and SEVIS (Student and Exchange Visitor Information System) certification of the college, transfer partnerships, location of the college, tuition, and living costs. The author emphasizes the importance of pre-planning and research when choosing a college and discusses some common mistakes made by international students.

Chapter 3 walks the reader through the steps of applying for admission to a community college. It's important for prospective international students to pay more attention to this chapter, especially to the application process, as it might be different from the process that they have in their home countries. Chapter 4 provides helpful information on the process of applying and obtaining an entry visa to the United States and how to maintain that visa status when already in the United States.

Chapter 5 offers details on travel and arrival procedures and the necessary documents to carry when traveling. This chapter is particularly helpful for those who are traveling first time to the U.S. Domestic travel options within the U.S. are also included in this chapter, which is helpful because many international students travel domestically when in the U.S.

Chapter 6 is perhaps one of the most critical and informative chapters in this book as it focuses on academics. Steps necessary to take upon arrival in order to register for classes could be very confusing for international students and having the information in chapter 6 handy would definitely be helpful. For example, the placement exams that a student must take might be something new to many international students and getting advice is necessary. Making sure to participate in orientation activities and getting advice to enroll in the "right" courses are also crucial for new international students. These topics are covered in chapter 6 as well.

Although brief advice on housing is given in chapter 6 , detailed information on living in the U.S. is provided in chapter 7. The author notes that dormitory housing is not common for community colleges and information on off-campus housing options are provided. Information on other practically important topics such as currency, bank accounts, credit cards, paying bills, phone and internet access, transportation, shopping, 
health care and emergencies, working in the U.S is also included in this chapter.

The remaining chapters in the book provide information on American people and their culture (Chapter 8), describe profiles of several community college located in different parts of the U.S. (Chapter 9), share voices of current international students (Chapter 10), and give explanation of terms commonly used in the American educational system (Chapter 11). Having preliminary knowledge about American society and values would be helpful for prospective international students because cultural shock is one of the primary challenges faced by international students as noted by the author.

Overall, the American Community Colleges: The International Student's Guide is a great educational resource for any prospective international student interested in obtaining undergraduate education in the United States. Moreover, this book, particularly chapters 6-8, is a very helpful resource for newly arrived international students who are in the process of registering for classes and settling in the new community. Web links of supplementary resources are provided at the end of each chapter with additional information on specific topics that are covered, which is another notable feature of this book. Finally, this book could also be used by community college recruiters who are interested in recruiting international students. The information provided in the book could be used to make a case for a community college being a first choice for international students.

NARA MARTIROSYAN is an Assistant Professor of Education in the Department of Educational Leadership at Sam Houston State University, Texas, USA. She teaches graduate courses in the fully online Doctoral Program in Developmental Education Administration and in the Master's Program in Higher Education Administration. Dr. Martirosyan has over 16 years of professional work experience in various educational settings both in Armenia and the United States. Her research interests include best practices in developmental education, factors affecting international students' adjustment, student satisfaction, assessment of student learning outcomes, and program evaluations in higher education. E-mail: nxm021@shsu.edu 